\title{
Potential role of p21 Activated Kinase 1 (PAK1) in the invasion and motility of oral cancer cells
}

\author{
Muraleedharan Parvathy ${ }^{1 \dagger}$, Sreeharshan Sreeja ${ }^{1 \dagger}$, Rakesh Kumar ${ }^{1,2}$ and Madhavan Radhakrishna Pillai ${ }^{1 *}$
}

From Indian Genetics Congress 2015

Kattankulathur, India. 4-6 March 2015

\begin{abstract}
Background: Oral cancer malignancy consists of uncontrolled division of cells primarily in and around the floor of the oral cavity, gingiva, oropharynx, lower lip and base of the tongue. According to GLOBOCAN 2012 report, oral cancer is one of the most common cancers among males and females in India. Even though significant advancements have been made in the field of oral cancer treatment modalities, the overall prognosis for the patients has not improved in the past few decades and hence, this demands a new thrust for the identification of novel therapeutic targets in oral cancer. p21 Activated Kinases (PAKs) are potential therapeutic targets that are involved in numerous physiological functions. PAKs are serine-threonine kinases and they serve as important regulators of cytoskeletal dynamics and cell motility, transcription through MAP kinase cascades, death and survival signalling, and cell-cycle progression. Although PAKs are known to play crucial roles in cancer progression, the role and clinical significance of PAKs in oral cancer remains poorly understood.
\end{abstract}

Results: Our results suggest that PAK1 is over-expressed in oral cancer cell lines. Stimulation of Oral Squamous Cell Carcinoma (OSCC) cells with serum growth factors leads to PAK1 re-localization and might cause a profound cytoskeletal remodelling. PAK1 was also found to be involved in the invasion, migration and cytoskeletal remodelling of OSCC cells.

Conclusions: Our study revealed that PAK1 may play a crucial role in the progression of OSCC. Studying the role of PAK1 and its substrates is likely to enhance our understanding of oral carcinogenesis and potential therapeutic value of PAKs in oral cancer.

Keywords: p21 Activated Kinase, Oral cancer, Invasion, Cytoskeletal remodelling, Migration

\section{Background}

According to GLOBOCAN 2012 [1], there has been 14.1 million new cancer cases, 8.2 million cancer deaths and 32.6 million people living with cancer worldwide within 5 years of diagnosis. Carcinoma of lip and oral cavity is one of the most frequent causes of cancer deaths among males. Ninety percent of oral cancers are OSCC [2],

\footnotetext{
* Correspondence: mrpillai@rgcb.res.in

${ }^{\dagger}$ Equal contributors

${ }^{1}$ Cancer Research, Rajiv Gandhi Centre for Biotechnology,

Thiruvananthapuram, Kerala, India

Full list of author information is available at the end of the article
}

originating from the flat cells (called squamous cells) that cover the surface of the oral cavity and oropharynx. With the advent of modern techniques, our understanding about the pathogenesis of oral cancer has increased over a period of time. But despite this, oral cancer has one of the lowest survival rates- 50 percent, within a five-year period (http://www.oralcancerfoundation.org/facts/). This calls for the identification of new therapeutic targets and one such potential set of target molecules are p21 Activated Kinases (PAKs).

PAKs were one of the first classes of Rho-GTPasesregulated kinases [3] to be identified. PAKs are a family 
of evolutionarily conserved group of serine-threonine kinases. So far, six PAK family members have been identified in mammals [4] and they have been classified into two sub-groups- Group I PAKs (PAKs 1-3) and Group II PAKs (PAKs 4-6). While Group I PAKs are activated by a variety of GTPase -dependent and -independent mechanisms, Group II PAKs are constitutively activated. PAKs are considered prime regulators of the actin cytoskeleton and motility [5]. Due to their central role in actin remodelling and their ability to activate Matrix metalloproteinases (MMPs), Rho GTPases play an important role in tumor cell invasion and metastasis [6]. The current evidence suggests the involvement of PAKs in motility [7-10], cell survival $[11,12]$, anchorageindependent growth [13], angiogenesis [14-18], invasion [18, 19], migration [20, 21] and regulation of cell cycle and mitosis [22, 23]. Consequently, PAKs have also been implicated in a number of pathological conditions including cancer [24].

Our interest resides in the PAK1 kinase, a member of group I PAKs. The roles of PAK1 in breast [25-30], colon [31-33], lung [34, 35], melanoma [36], prostate [37, 38], ovarian cancers [39] are well studied. Even though PAKs are known to play roles in the crucial steps of cancer progression, its role and clinical significance in oral cancer remains ill defined. In this work, we investigated the role of PAK1 in oral cancer. Our study suggests that PAK1 plays a crucial role in the progression of oral cancer and represents a potential therapeutic target in OSCC.

\section{Results and Discussion}

OSCC cell lines showed differential expression and localization patterns for PAK1

Very few studies have elucidated the expression pattern of PAK1 in OSCC cell lines. We analysed the expression and localization patterns of PAK1 in the five OSCC cell lines. Our study demonstrated that all the five OSCC cell lines differentially expressed PAK1 (Fig. 1a).

Localization pattern of proteins play a key role in cancer. Previous studies have shown that PAK1 localizes in the cytoplasm, nucleus or to the cell membrane. An earlier study had demonstrated that PAK1 expression in breast tumors positively correlated with tumor grade, with higher expression in grade 3 [40]. Another study involving an established murine model of breast cancer progression had shown that PAK1 expression and its nuclear localization were progressively increased during the transition from ductal hyperplasia to ductal carcinoma in situ to adenocarcinoma [41]. Holm et al. [42] had suggested that PAK1 activation and its nuclear localization may be one of the mechanisms responsible for reduced tamoxifen sensitivity of breast tumor cells. Even though there are studies in other cancer types that
A

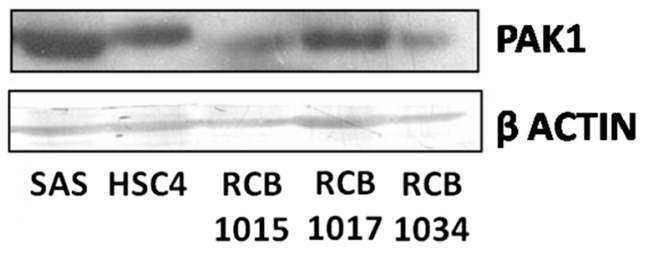

B
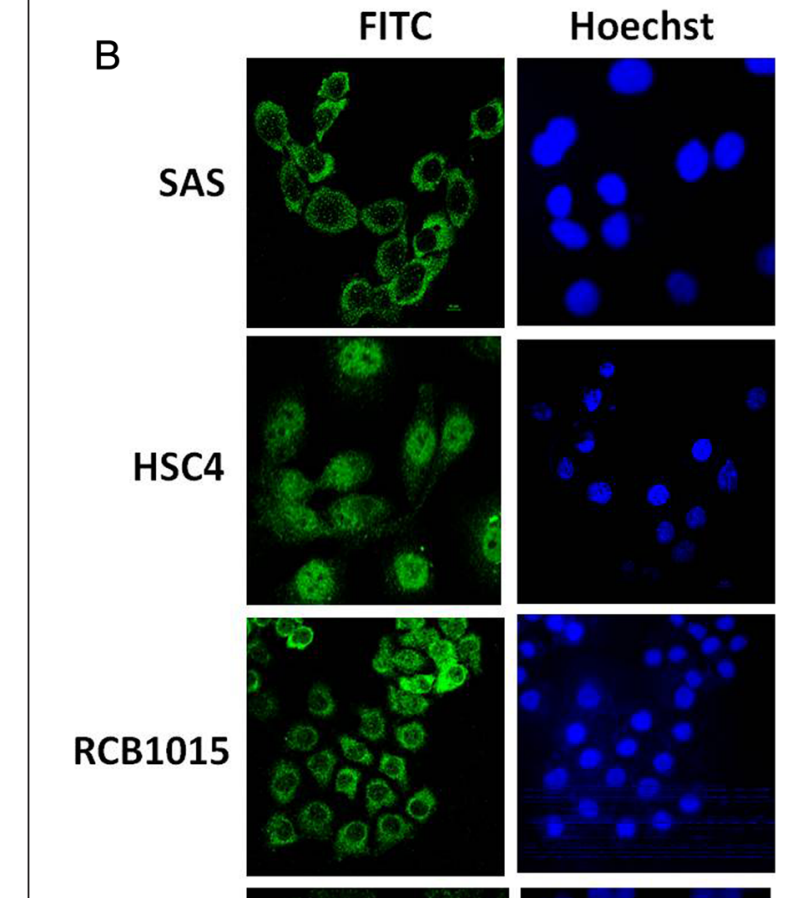

RCB1017

RCB1034
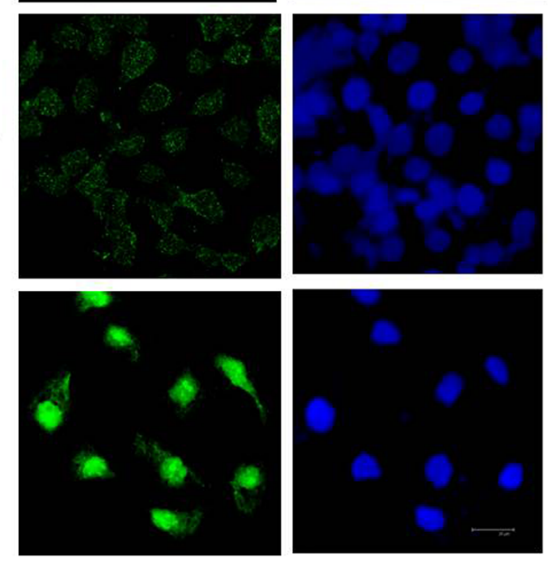

Fig. 1 Expression and localization patterns of PAK1 in the five OSCC cell lines. a OSCC cell lines (SAS, HSC4, RCB1015, RCB1017 and RCB1034) used in our study showed differential expression levels of PAK1. b PAK1 exhibited differential localization patterns in OSCC cell lines. PAK1 predominantly localized in the nucleus in HSC4 cells, whereas in SAS and RCB1015, PAK1 showed a predominant cytoplasmic localization. While in RCB1017, PAK1 was found in both nuclear and cytoplasmic compartments, in RCB1034, PAK1 was mostly showing nuclear localization pattern 
correlated the localization patterns and cancer progression, this issue has not been investigated in oral cancer as yet.

To study the localization patterns of PAK1 in OSCC cell lines, confocal microscopy was performed in OSCC cell lines which were exponentially growing in $10 \%$ Foetal Bovine Serum containing medium. The results of confocal microscopy revealed that PAK1 predominantly localizes in the nucleus of HSC4 cells and RCB1034 cells, while in SAS cells and RCB1015, PAK1 was predominantly in the cytoplasm (Fig. 1b). In the case of RCB1017, PAK1 was observed in both the nuclear and cytoplasmic compartments.

\section{Differential localization of PAK1 and cytoskeleton remodelling in serum-stimulated OSCC cells}

Growth factors and their receptors play a very crucial role in cancer progression. Previous reports suggested that over-expression of Epidermal Growth Factor Receptor (EGFR) [43] and Transforming Growth Factor $\beta 1$ (TGF $\beta 1$ ) [44] are associated with increased malignant potential and correlated with poor treatment outcome in head and neck cancer. Growth factors are known to recruit PAKs to the membranes, where they come in contact with other activating kinases, leading to the downstream signalling cascade.

To study the effect of serum growth factors on the localization of PAK1, HSC4 cells were grown in serum free condition. After $48 \mathrm{~h}$, cells were cultured in the presence of medium containing $10 \%$ serum for varying time intervals and the localization patterns of PAK1 were studied. It was observed that in serum-free condition, PAK1 predominantly resides in the nucleus, but upon stimulation with serum, PAK1 largely accumulates in the cytoplasm (Fig. 2a). This suggests that PAK1 localization is regulated by the growth factors and in-turn, differential sub-cellular PAK1 localization may influence its ability to trigger cytoskeleton remodelling in the cytoplasm.

To analyse the effect of growth factors on actin remodelling in OSCC, HSC4 cells were grown in serum free condition. After $48 \mathrm{~h}$, cells were cultured in medium containing $10 \%$ serum for varied time intervals and Phalloidin staining was done after fixing the cells. As shown in Fig. 2b, actin was mostly in the condensed form and was concentrated mostly in the periphery of the cells grown in serum-free conditions. However, a more prominent actin network was visible in serumstimulated cells. These observations suggest that PAK1 predominantly localizes in the nucleus in serum-starved OSCC cells with a condensed actin network. However, PAK1 translocates to the cytoplasm in serum-stimulated cells wherein it might participate in actin remodelling. Further experiments would provide conclusive evidence regarding the suggested role of PAK1 in regulating the cytoskeletal structures of OSCC cells.

\section{Potential role of PAK1 in the cytoskeletal remodelling, invasiveness and motility of OSCC cells}

Cytoskeletal remodelling plays an essential role in the cell motility. For a productive cancer progression, the malignant cells must undergo dynamic changes in
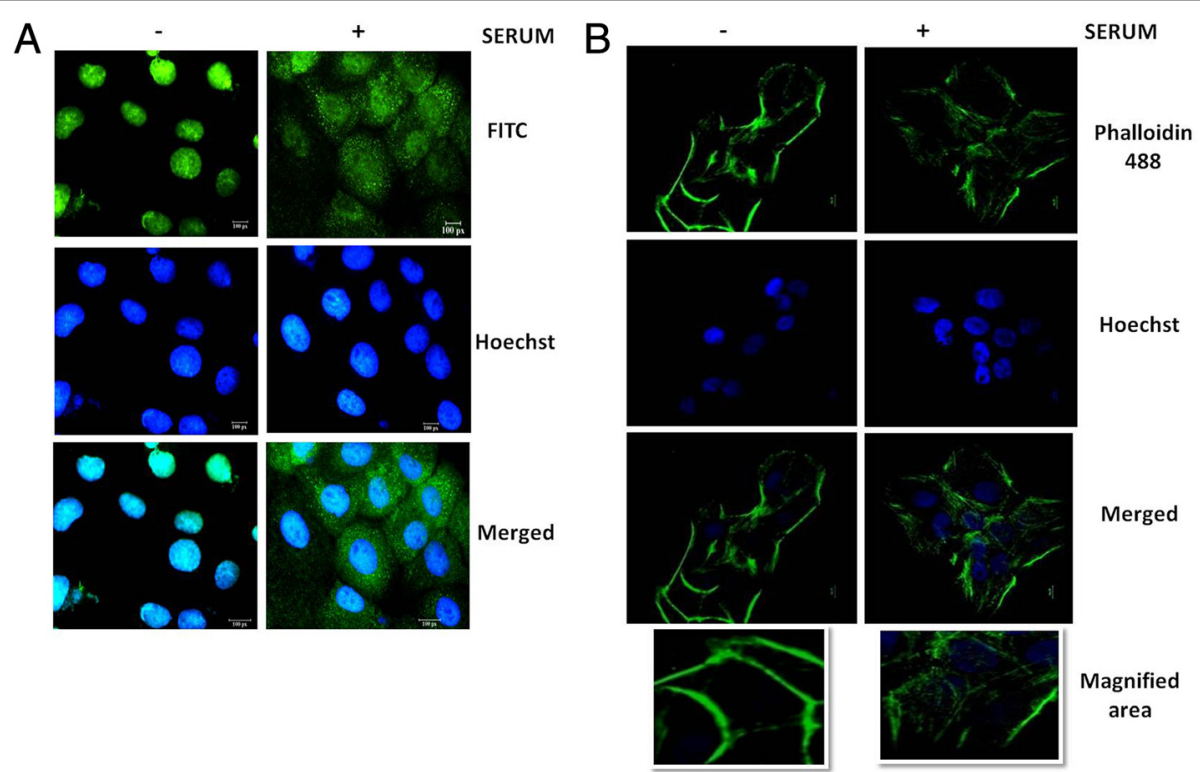

Fig. 2 Effect of serum growth factors on PAK1 localization and its potential role in regulating actin cytoskeletal structures. HSC4 cells were serum starved for $48 \mathrm{~h}$ and treated with or without medium containing $10 \%$ FBS for varying intervals of time. One set of plates were subjected to localization studies (a) while the second set was stained with Phalloidin 488 (b) 
cytoskeletal structure, thereby enabling the cancer cells to migrate and invade the neighbouring tissues. As mentioned earlier, PAK1 has been implicated in the progression of different cancer types. However, its role in oral cancer remains poorly studied. To study the effect of PAK1 in the cytoskeletal remodelling, motility and invasiveness of OSCC cells, PAK1 was selectively knocked down in the SAS cells (Fig. 3a) and such cells were subjected to Phalloidin staining, wound healing assay and Matrigel invasion assay. Phalloidin staining of control and PAK1 kock-down SAS cells (Fig. 3b) demonstrated that the actin structures and the morphology of the cells were intact in the control cells with PAK1, while these structures were profoundly reorganized in OSCC cells with depleted PAK1, indicating that PAK1 might be essential for cytoskeletal remodelling of OSCC cells. Further experiments are required to establish the role of PAK1 in cytoskeletal remodelling of OSCC cells.

To study the motility of OSCC cells with or without PAK1 knock-down, we next performed Wound healing assay. It was observed that even after $24 \mathrm{~h}$ of growing the cells with PAK1 knock-down in serum containing medium, the wound was not completely healed (Fig. 3c) as compared to the control cells with almost a complete wound healing. To exclude a potential influence of expected proliferation difference in $10 \%$ FBS-containing medium, a set of cells were also grown in growth factorfree medium. This observation suggested that PAK1 may be involved in the motility of growth-factor stimulated OSCC cells.

Another pre-requisite for cancer progression is the ability of cancer cells to invade into the neighbouring normal tissue, thereby facilitating the process of metastasis. To study the involvement of PAK1 in this process, we subjected OSCC cells with or without PAK1 knockdown to Matrigel invasion assay. It was observed that when compared to the control cells, cells with PAK1 knock-down showed almost four fold decrease in the invasiveness, suggesting that PAK1 is also involved in the invasiveness of OSCC cells (Fig. 3d).

Additionally, we had done an in-silico analysis to survey PAK1 phosphorylation sites in differentially expressed genes in OSCC by using the software GPS (Group-based prediction system) 2.1 [45]. Out of the 64 genes that are differentially expressed in OSCC, 26 genes (Additional file 1) were found to have PAK1 phosphorylation sites. Further functional studies are required to confirm this in-silico finding.

\section{Conclusions}

We had ventured into an under-investigated area in cancer biology i.e., the role of PAK1 in the progression of OSCC. PAK1 was found to be differentially expressed and localized in OSCC cell lines used for our study. Because growth factors are potent inducers of PAK1 activation, we studied the response of OSCC cells by

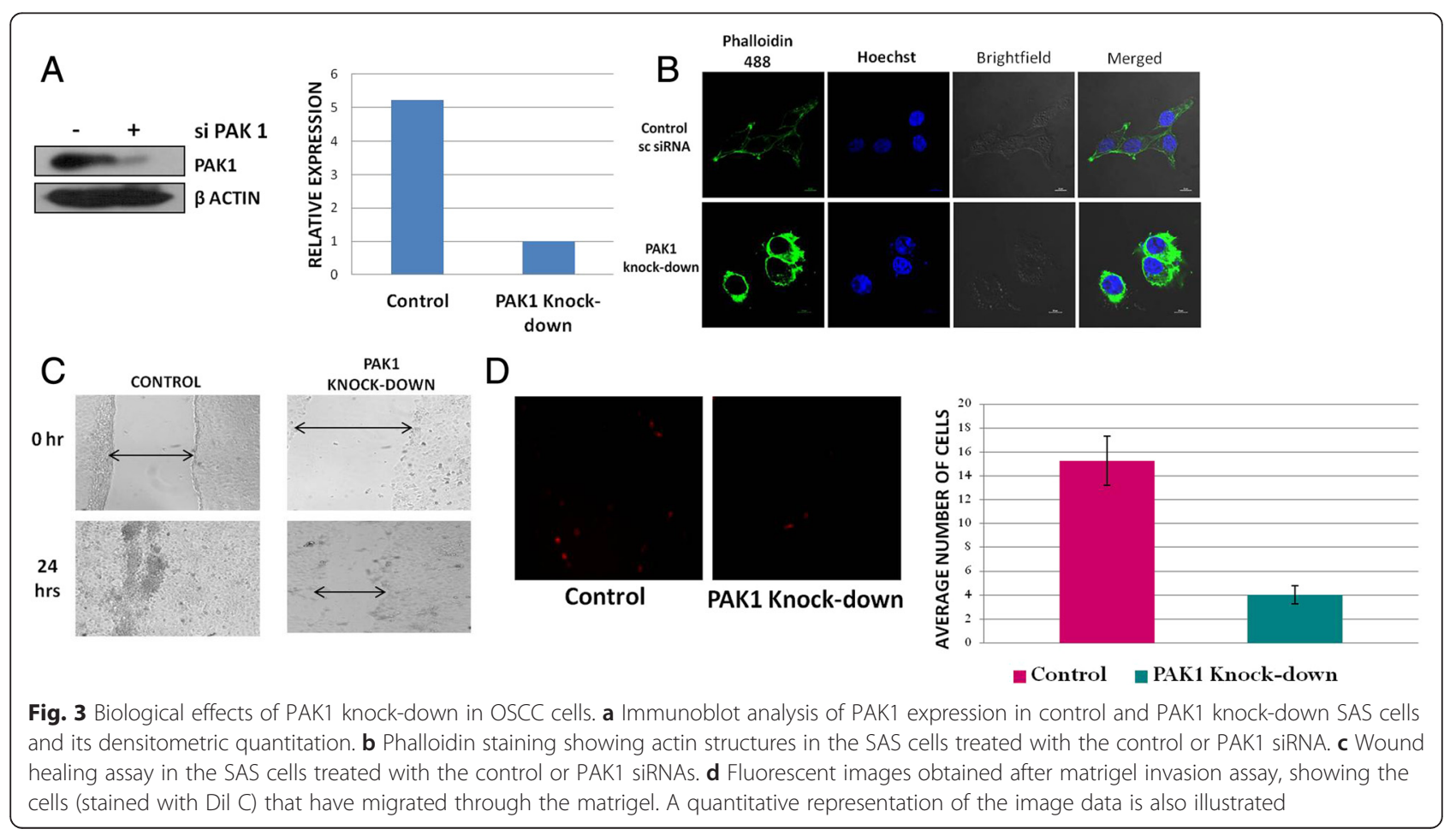


serum growth factors. It was observed that serum growth factors facilitate the translocation and/or accumulation of PAK1 in distinct sub-cellular compartments, and also, it might affect the cytoskeletal structures of OSCC cells. Migration and invasion of cancer cells are under the control of dynamic cytoskeletal re-organization, in addition to other pathways. We found that PAK1 plays a potential role in cytoskeletal remodelling of OSCC cells, thereby affecting the motility and invasiveness of OSCC cells. Further studies are required to bring out the mechanistic insights into the role of PAK1 in oral cancer progression. In brief, PAK1 plays a crucial role in OSCC progression and that studying the role of PAK1 could improve our understanding of oral carcinogenesis and in determining new therapeutic targets for oral cancer.

\section{Methods}

\section{Cell culture}

Oral cancer cell lines like SAS, HSC4, RCB 1015, RCB1017 and RCB1034 were used for the study. Out of this, SAS and HSC4 are human tongue squamous cell carcinoma cell line whereas RCB1015, RCB1017 and RCB1034 are OSCC cell line obtained from the same patient in different stages of tumor progression. RCB1015 is a G-CSF producing OSCC cell line, RCB1017 is a G-CSF and IL-1 producing oral squamous cell carcinoma whereas, RCB1034 is a human cell line derived from metastasis of cancer occurred in oral cavity. All the cell lines were obtained from Riken BRC (BioResource Center) Cell bank, Japan. The cells were grown in Dulbecco's modified Eagles medium (DMEM) (Sigma-Aldrich, St. Louis, MO) and RPMI 1640 medium (developed at Roswell Park Memorial Institute) supplemented with $10 \%$ heat-inactivated fetal bovine serum (FBS; Invitrogen), and antibiotic and anti-mycotic cocktail (Lonza).

\section{Immunoblot analysis}

Immunoblot analysis was done as mentioned in Haneef et al. [46]. Briefly, cells were washed with PBS and lysed using RIPA (Radioimmunoprecipitation assay) buffer $(150 \mathrm{mM} \mathrm{NaCl}, 1$ \% NP-40, 0.5 \% Sodium deoxycholate, $0.1 \%$ SDS, $50 \mathrm{mM}$ Tris- $\mathrm{HCl} \mathrm{pH}$ 7.4) containing protease inhibitor cocktail (Sigma-Aldrich Inc., USA). Briefly, equal amount of protein as determined by Bradford assay was subjected to SDS-PAGE, followed by transfer to nitrocellulose membrane (Millipore, MA). The membrane was then blocked in $5 \%$ powdered non-fat milk Tris solution for $1 \mathrm{~h}$. Membrane was then incubated overnight with primary antibody, followed by incubation with species-specific horseradish peroxidase (HRP) conjugated secondary antibody (1:5000, Santa Cruz) at room temperature for $1 \mathrm{~h}$. Protein bands were visualised on Xray film using ECL-plus reagents (Amersham, NJ). The primary antibodies were: PAK1 (1:5000, Bethyl Labs) and Beta actin (1:5000, Sigma).

\section{Confocal immunofluorescent microscopy and phalloidin staining}

The oral cell lines (SAS, HSC4, RCB1015, RCB1017 and RCB1034) were cultured on glass coverslips until 60$70 \%$ confluence. Cells were fixed in chilled $4 \%$ paraformaldehyde solution in PBS at $4{ }^{\circ} \mathrm{C}$ for $7 \mathrm{~min}$ and then permeabilized with $0.1 \%$ Triton $\mathrm{X} 100$ for $7 \mathrm{~min}$ at room temperature, followed by three washes using PBS. Non-specific protein binding was reduced by incubation in $3 \%$ BSA at room temperature for $1 \mathrm{~h}$. The cells were then incubated with primary antibodies for PAK1 (dilution: $1: 500$ ) at $4{ }^{\circ} \mathrm{C}$ for overnight. The cells were washed twice with PBS, followed by incubation with secondary antibody conjugate for $1 \mathrm{~h}$ at room temperature and nuclear staining was done using Hoechst staining $(5 \mu \mathrm{g} / \mathrm{ml})$ for $5 \mathrm{~min}$. For Phalloidin staining, the cells were treated with Alexa Fluor 488 Phalloidin (dilution: $5 \mu \mathrm{M}$ ) for 20 min. After giving a wash with PBS twice, the cells were stained with the nuclear dye Hoechst 33342 (Invitrogen, $5 \mu \mathrm{g} / \mathrm{ml}$ ). Again, the cells were washed twice in PBS. The coverslips were mounted in Glycerol on glass slides and sealed with nail polish. Microscopic observations were made using laser scanning confocal microscope (Nikon A1R). Localization pattern of PAK1 was studied using Immunofluorescent detection of the protein while F-Actin structure was studied using Phalloidin staining.

\section{siRNA transfection}

SAS cells were seeded on 6 well plates and incubated for $48 \mathrm{~h}$ in complete medium. The cells were transfected with 100nM of siRNA specific for human PAK1 (pSUPER PAK1 siRNA) or control siRNA (sc-37007, Santacruz) using the Lipofectamine LTX and PLUS siRNA transfection reagents as per the manufacturer's instruction. $12 \mathrm{~h}$ after transfection, transfection medium was replaced with fresh medium containing serum and allowed to grow for $24 \mathrm{~h}$. Whole cell extract was prepared $36 \mathrm{~h}$ after transfection for analysis of silencing efficiency by western blot using antibody against PAK1 (Bethyl Labs, A301-259A).

\section{Matrigel invasion assay}

The cell invasion assay was conducted using BioCoat Matrigel (Becton Dickinson Biosciences) by following the manufacturer's protocol. After transfection with either anti-PAK1 or control siRNAs, cells were seeded into the upper chamber at a density of $1 \times 10^{5}$ cells per well in $0.2 \mathrm{ml}$ of $1 \%$ FBS medium. The lower chamber contained complete culture medium, which included $10 \%$ FBS to attract invading cells. Cells were incubated 
at $37^{\circ} \mathrm{C}$ for $24 \mathrm{~h}$, and the number of cells that invaded through the Matrigel-coated membranes was counted and compared with the number of cells that passed through the membrane in the control chambers. The invaded cells on lower side of membrane were fixed, stained with Dil C stain, and photographed.

\section{Wound healing assay}

Cell migration was evaluated by an in vitro woundhealing assay. After transfection with either anti-PAK1 or scramble siRNAs, $5 \times 10^{5} \mathrm{cell} / \mathrm{ml}$ transfectants was seeded in a 24 well plate. After the culture had formed a monolayer, a cell-free gap was produced with the help of a yellow tip. After changing to culture medium with $1 \%$ FBS, the cell migration status toward the gap area was photographed after $24 \mathrm{~h}$.

\section{Additional file}

Additional file 1: The FASTA sequences of differentially expressed genes were examined using GPS2.1 software to analyse the presence of PAK1 phosphorylation sites. Using highly stringent condition, we recognized 26 genes with putative PAK1 phosphorylation sites. (XLSX $10 \mathrm{~kb}$ )

\section{Abbreviations}

DMEM: Dulbecco's modified eagles medium; EGFR: Epidermal Growth Factor Receptor; FBS: Foetal Bovine Serum; GPS2.1: Group-based prediction system 2.1; GTPases: Guanosine TriPhosphatases; HRP: Horseradish peroxidase; KD: knock-down; mM: milli molar; MMPs: matrix metalloproteinases; OSCC: Oral Squamous Cell Carcinoma; PAK1: p21 Activated Kinase 1; PBS: phosphate buffered saline; RIPA: Radioimmunoprecipitation assay; TGF $\beta 1$ : Transforming Growth Factor $\beta 1 ; \mu \mathrm{g} / \mathrm{ml}$ : microgram per milliliter.

\section{Competing interests}

The authors declare that they have no competing interests.

\section{Authors' contributions}

R.K, M.R.P and S.S designed the study. M.P did the experimental part. M.P and S.S drafted the manuscript. All authors helped in revising the manuscript and accepted its final version. M.P. and S.S. share equal authorship.

\section{Acknowledgements \\ The authors gratefully appreciate the support by grants for Mrs. Muraleedharan Parvathy by Senior Research Fellowship from the Council of Scientific and Industrial Research (CSIR), Government of India (CSIR AWARD NO. 09/716(0125)/ 2009-EMR-I). The study was funded by the Department of Biotechnology, Government of India. The views and opinions expressed in this article are those of the authors. We wish to thank the technical support by Mr. Anurup KG for confocal microscopy.}

\section{Declarations}

The publication cost for this article was funded by the Department of Biotechnology, Government of India.

This article has been published as part of BMC Cancer Volume 16 Supplement 1, 2016: Proceedings of the Indian Genetics Congress 2015: Cancer. The full contents of the supplement are available online at https://bmccancer.biomedcentral.com/articles/supplements/volume-16supplement-1.

\section{Author details}

${ }^{1}$ Cancer Research, Rajiv Gandhi Centre for Biotechnology, Thiruvananthapuram, Kerala, India. ${ }^{2}$ Department of Biochemistry and Molecular Medicine, George Washington University, Washington DC, USA

Published: 16 May 2016

\section{References}

1. Ferlay J, Soerjomataram I, Ervik M, Dikshit R, Eser S, Mathers C, Rebelo M, Parkin DM, Forman D, Bray, F. GLOBOCAN 2012 v1.0, Cancer Incidence and Mortality Worldwide: IARC Cancer Base No. 11 [Internet]. Lyon, France: International Agency for Research on Cancer; 2013. Available from: http://globocan.iarc.fr, accessed on 04/05/2014.

2. Johnson N, Franceschi S, Ferlay J, Ramadas K, Schmid S, MacDonald DG, Bouquot JE, Slootweg PJ. Squamous cell carcinoma. In: Barnes L, Eveson JW, Reichart P, Sidransky D, editors. Pathology \& Genetics Head and Neck Tumours. Lyon: IARC Press; 2005. p. 168-75.

3. Manser E, Leung T, Salihuddin H, Zhao ZS, Lim L. A brain serine threonine protein-kinase activated by Cdc42 and Rac1. Nature. 1994;367:40-6.

4. Hofmann C, Shepelev M, Chernoff J. The genetics of PAK. J Cell Sci. 2004;117:4343-54.

5. Sells MA, Knaus UG, Bagrodia S, Ambrose DM, Bokoch GM, Chernoff J. Human p21-activated kinase (PAK1) regulates actin organization in mammalian cells. Curr Biol. 1997;7:202-10.

6. Lozano E, Betson M, Braga VM. Tumor progression: Small GTPases and loss of cell-cell adhesion. Bioessays. 2003;25:452-63.

7. Sells MA, Boyd JT, Chernoff J. p21-Activated Kinase 1 (PAK1) Regulates Cell Motility in Mammalian Fibroblasts. J Cell Biol. 1999;145:837-49.

8. Nayal A, Webb DJ, Brown CM, Schaefer EM, Vincente-Manzanares M, Horwitz AR. Paxillin phosphorylation at Ser273 localizes a GIT1-PIX-PAK complex and regulates adhesion and protrusion dynamics. J Cell Biol. 2006;173:587-9.

9. Brown MC, West KA, Turner CE. Paxillin-dependent paxillin kinase linker and p21-activated kinase localization to focal adhesions involves a multistep activation pathway. Mol Biol Cell. 2002;13:1550-65.

10. Premont RT, Perry SJ, Schmalzigaug R, Roseman JT, Xing Y, Claing A. The GIT/PIX complex: an oligomeric assembly of GIT family ARF GTPaseactivating proteins and PIX family Rac1/Cdc42 guanine nucleotide exchange factors. Cell Signal. 2004;16:1001-11.

11. Knaus UG, Bokoch GM. The p21Rac/Cdc42-activated kinases (PAKs). Int J Biochem Cell Biol. 1998;30:857-62.

12. Gnesutta N, Minden A. Death receptor-induced activation of initiator caspase 8 is antagonized by serine/threonine kinase PAK4. Mol Cell Biol. 2003;23:7838-48.

13. Bagheri-Yarmand R, Mandal M, Talukdar AH, Wang RA, Adam L, Vadlamudi RK, Kung SJ and Kumar R. Etk/Bmx tyrosine kinase activates PAK-1 and regulates the tumorigenecity of breast cancer cells. J Biol Chem. 2001:276:29403-9.

14. Hu GD, Chen YH, Zhang L, Tong WC, Cheng YX, Luo YL, Cai SX, Zhang L. The generation of the endothelial specific cdc42-deficient mice and the effect of cdc42 deletion on the angiogenesis and embryonic development. Chin Med J (Engl). 2011;124:4155-9.

15. Srinivasan R, Zabuawala T, Huang H, Zhang J, Gulati P, Fernandez S, Karlo JC, Landreth GE, Leone G, Ostrowski MC. Erk1 and Erk2 regulate endothelial cell proliferation and migration during mouse embryonic angiogenesis. PLoS One. 2009;4:e8283.

16. Tan W, Palmby TR, Gavard J, Amornphimoltham P, Zheng Y, Gutkind JS. An essential role for Rac1 in endothelial cell function and vascular development. FASEB J. 2008;22:1829-38.

17. Conway RE, Petrovic N, Li Z, Heston W, Wu D, Shapiro LH. Prostate-specific membrane antigen regulates angiogenesis by modulating integrin signal transduction. Mol Cell Biol. 2006;26:5310-24.

18. Adam L, Vadlamudi R, Mandal M, Chernoff J, Kumar R. Regulation of microfilament reorganization and invasiveness of breast cancer cells by kinase dead p21-activated kinase-1. J Biol Chem. 2000;275:12041-50.

19. Goc A, Al-Azayzih A, Abdalla M, Al-Husein B, Kavuri S, Lee J, Moses K, Somnath PR. P21 activated kinase-1 (PAK1) promotes prostate tumor growth and microinvasion via inhibition of transforming growth factor beta expression and enhanced matrix metalloproteinase 9 secretion. J Biol Chem. 2013;288:3025-35.

20. Kiosses WB, Daniels RH, Otey C, Bokoch GM, Schwartz MA. A role for p21activated kinase in endothelial cell migration. J Cell Biol. 1999;147:831-44.

21. Del Valle-Perez B, Martinez VG, Lacasa-Salavert C, Figueras A, Shapiro SS, Takafuta T, Casanovas O, Capellà G, Ventura F, Viñals F. Filamin B plays a key role in vascular endothelial growth factor-induced endothelial cell motility through its interaction with Rac-1 and Vav-2. J Biol Chem. 2010;285:10748-60.

22. Bompard G, Rabeharivelo G, Cau J, Abrieu A, Delsert C, Morin N. P21activated kinase 4 (PAK4) is required for metaphase spindle positioning and anchoring. Oncogene. 2013;32:910-9. 
23. Bompard G, Rabeharivelo G, Frank M, Cau J, Delsert C, Morin N. Subgroup II PAK-mediated phosphorylation regulates Ran activity during mitosis. J Cell Biol. 2010;190:807-22.

24. Ye DZ, Field J. PAK signaling in cancer. Cell Logist. 2012;2:105-16.

25. Bostner J, Ahnström Waltersson M, Fornander T, Skoog L, Nordenskjöld B, Stål O. Amplification of CCND1 and PAK1 as predictors of recurrence and tamoxifen resistance in postmenopausal breast cancer. Oncogene. 2007;26:6997-7005.

26. Balasenthil S, Sahin AA, Barnes CJ, Wang RA, Pestell RG, Vadlamudi RK, Kumar R. P21-activated kinase-1 signaling mediates cyclin D1 expression in mammary epithelial and cancer cells. J Biol Chem. 2004;279:1422-8.

27. Shrestha Y, Schafer EJ, Boehm JS, Thomas SR, He F, Du J, Wang S, Barretina J, Weir BA, Zhao JJ, Polyak K, Golub TR, Beroukhim R, Hahn WC. PAK1 is a breast cancer oncogene that coordinately activates MAPK and MET signaling. Oncogene. 2012;31:3397-408.

28. Rayala SK, Talukder AH, Balasenthil S, Tharakan R, Barnes CJ, Wang RA, Aldaz CM, Khan S, Kumar R. P21-activated kinase 1 regulation of estrogen receptor-alpha activation involves serine 305 activation linked with serine 118 phosphorylation. Cancer Res. 2006;66:1694-701.

29. Wang RA, Mazumdar A, Vadlamudi RK, Kumar R. P21-activated kinase-1 phosphorylates and transactivates estrogen receptor-alpha and promotes hyperplasia in mammary epithelium. EMBO J. 2002;21:5437-47.

30. Du J, Sun C, Hu Z, Yang Y, Zhu Y, Zheng D, Gu L, Lu X. Lysophosphatidic acid induces MDA-MB-231 breast cancer cells migration through activation of PI3K/PAK1/ERK signaling. PLoS One. 2010;5:e15940.

31. Carter JH, Douglass LE, Deddens JA, Colligan BM, Bhatt TR, Pemberton JO, Konicek S, Hom J, Marshall M, Graff JR. PAK-1 expression increases with progression of colorectal carcinomas to metastasis. Clin Cancer Res. 2004;10:3448-56.

32. Zhu G, Wang Y, Huang B, Liang J, Ding Y, Xu A, Wu W. A Rac1/PAK1 cascade controls beta-catenin activation in colon cancer cells. Oncogene. 2012:31:1001-12.

33. Huynh N, Liu KH, Baldwin GS, He H. P21-activated kinase 1 stimulates colon cancer cell growth and migration/invasion via ERK- and AKT-dependent pathways. Biochim Biophys Acta. 2010;1803:1106-13.

34. Ong CC, Jubb AM, Haverty PM, Zhou W, Tran V, Truong T, Turley H, O'Brien T, Vucic D, Harris AL, Belvin M, Friedman LS, Blackwood EM, Koeppen H, Hoeflich KP. Targeting p21-activated kinase 1 (PAK1) to induce apoptosis of tumor cells. Proc Natl Acad Sci U S A. 2011;108:7177-82.

35. Kissil JL, Walmsley MJ, Hanlon L, Haigis KM, Bender Kim CF, Sweet-Cordero A, Eckman MS, Tuveson DA, Capobianco AJ, Tybulewicz VL, Jacks T. Requirement for Rac1 in a K-ras induced lung cancer in the mouse. Cancer Res. 2007;67:8089-94.

36. Ong CC, Jubb AM, Jakubiak D, Zhou W, Rudolph J, Haverty PM, Kowanetz M, Yan Y, Tremayne J, Lisle R, Harris AL, Friedman LS, Belvin M, Middleton MR, Blackwood EM, Koeppen H, Hoeflich KP. P21-activated kinase 1 (PAK1) as a therapeutic target in BRAF wild-type melanoma. J Natl Cancer Inst. 2013;105:606-7.

37. Al-Azayzih A, Gao F, Somanath PR. P21 activated kinase-1 mediates transforming growth factor $\beta 1$-induced prostate cancer cell epithelial to mesenchymal transition. Biochim Biophys Acta. 2015;1853:1229-39.

38. Shin YJ, Kim EH, Roy A, Kim JH. Evidence for a novel mechanism of the PAK1 interaction with the Rho-GTPases Cdc42 and Rac. PLoS One. 2013;8:e71495.

39. Brown LA, Kalloger SE, Miller MA, Shih IM, McKinney SE, Santos JL, Swenerton K, Spellman PT, Gray J, Gilks CB, Huntsman DG. Amplification of 11q13 in ovarian carcinoma. Genes, Chromosomes Cancer. 2008;47:481-9.

40. Rayala SK, Molli PR, Kumar R. Nuclear p21-Activated Kinase 1 in Breast Cancer Packs Off Tamoxifen Sensitivity. Cancer Res. 2006;66:5985-8.

41. Wang RA, Zhang H, Balasenthil S, Medina D, Kumar R. PAK1 hyperactivation is sufficient for mammary gland tumor formation. Oncogene. 2006;25:2931-6.

42. Holm C, Rayala SK, Jirstorm K, Stal O, Kumar R, Landberg G. Association between PAK1 expression and subcellular localization and tamoxifen resistance in breast cancer patients. J Natl Cancer Inst. 2006;98:671-80.

43. Myers JN, Holsinger FC, Beckele BN, Li E, Jasser SA, Killion JK, Fidler IJ. Targeted Molecular Therapy for Oral Cancer with Epidermal Growth Factor Receptor Blockade. Arch Otolaryngol Head Neck Surg. 2002;128:875-9.

44. Sun L, Diamond ME, Ottaviano AJ, Joseph MJ, Ananthanarayan V, Munshi HG. Transforming Growth Factor-B1 Promotes Matrix Metalloproteinase-9-Mediated Oral Cancer Invasion through Snail Expression. Mol Cancer Res. 2008;6:10-20.

45. Xue Y, Liu Z, Cao J, Ma Q, Gao X, Wang Q, Jin C, Zhou Y, Wen L, Ren J. GPS 2.1: enhanced prediction of kinase-specific phosphorylation sites with an algorithm of motif length selection. Protein Engineering. Design and Selection. 2011:24:255-60.

46. Haneef J, Parvathy M, Thankayyan RSK, Sithul H, Sreeharshan S. Bax Translocation Mediated Mitochondrial Apoptosis and Caspase Dependent Photosensitizing Effect of Ficus religiosa on Cancer Cells. PLoS One. 2012;7(7):e40055.

\section{Submit your next manuscript to BioMed Central and we will help you at every step:}

- We accept pre-submission inquiries

- Our selector tool helps you to find the most relevant journal

- We provide round the clock customer support

- Convenient online submission

- Thorough peer review

- Inclusion in PubMed and all major indexing services

- Maximum visibility for your research

Submit your manuscript at www.biomedcentral.com/submit
Biomed Central 